\title{
The Effect of Psychosocial Work Environment on Psychological Strain among Banking Employees in Malaysia
}

\author{
Nurul Farhana Mohd Noordin ${ }^{1} \&$ Siti Aisyah Panatik ${ }^{1}$ \\ ${ }^{1}$ Faculty of Management, Universiti Teknologi Malaysia, Malaysia \\ Correspondence: Nurul Farhana Mohd Noordin, Faculty of Management, Universiti Teknologi Malaysia, \\ Malaysia. E-mail: farhananoordin@gmail.com
}

Received: September 22, 2015

Accepted: October 20, 2015 Online Published: November 20, 2015

doi:10.5539/ass.v11n27p287

URL: http://dx.doi.org/10.5539/ass.v11n27p287

\begin{abstract}
This study was conducted to examine the psychosocial work environment dimensions as predictors of psychological strain among bank employees specifically bank tellers. The restructuring of financial institutions exposed banking employees to stressful conditions such as unfeasible sales target, lower salaries, high workload and job insecurity. These conditions lead to adverse health outcomes. The researcher integrated the effort-reward imbalance model and the organizational justice model as the psychosocial work environment dimensions that represent the stressful working condition. Thus, these dimensions were hypothesized to affect psychological strain in terms of anxiety, depression and social dysfunction. The data was collected quantitatively by distributing questionnaires to employees in a Malaysian domestic bank. A total number of 306 respondents participated in this study. The data was analysed by performing structural equation modeling using AMOS 22 . The finding indicates that effort, reward, overcommitment, procedural justice and interactional justice significantly affect psychological strain. Only effort-reward ratio was not significant in predicting psychological strain. These findings added the empirical evidence in the stress-strain literature that involves psychosocial work environment specifically among banking employees in Malaysian context.
\end{abstract}

Keywords: effort-reward imbalance, organizational justice, psychological strain

\section{Introduction}

Banking is one of the sectors that have undergone major growth due to globalization. This is unexceptional in Malaysia where the banking institutions have to cope with technological advancement, managerial changes and global competition (Ang et al., 2014). The growth and advancement in banking including automated teller machine (ATM) usage, retail banking, online banking, debit and credit cards, inter-bank and intra-bank transfer, insurance policies, loans and trust funds. The changing of working environment by implementing new technology and new procedure lead to work-related stress among banking employees. As frontline employees, bank tellers have to deal with the changes in their working environment as well as confronting the customers. Furthermore, the current banking structure requires bank tellers to possess new skills such as selling and marketing skills to attract the customers (Khoo, 2012). They experienced intense work stress which will then lead to various negative outcomes including job dissatisfaction, poor work performances (Spector, 2007; Siti Aisyah Panatik, 2010).

This research intends to study the contributing factors of psychological strain among bank tellers in terms of their psychosocial work environment. Psychological strain refers to the psychological reaction caused by long exposure to work stress (Francis \& Barling, 2005). There are several theories that explain the effect of psychosocial work environment on psychological strain such as job demand-control model (Karasek, 1979), job demand-resources model (Bakker \& Demerouti, 2007), and effort-reward imbalance model (Siegrist et al., 1996). The present research utilizes the effort-reward imbalance (ERI) model and the organizational justice model to extract the elements of stressful psychosocial work environment that predicts psychological strain. The ERI model posits that the reward received at work should be adequate with the effort spent by the employees (Karasek, 1979). The perception of inadequacy between the contributed effort and the gained reward resulted in the employees' psychological strain. Organizational justice refers to the extent to which employee perceive the organization is being fair to them (Niehoff \& Moorman, 1993). The unfairness in the workplace has been considered as one types of psychosocial work environment that cause psychological strain (O'Driscoll et al., 
2010). Thus, the objective of this research is to investigate the effect of psychosocial work environment (i.e. effort-reward imbalance and organizational justice on psychological strain).

The integration of the effort-reward imbalance model and the organizational justice model as predictor variables in this research captures a wider range of social context in the working environment. The ERI model covers the work contract that exists between the employers and their employees (Siegrist, 2009). The inequity of effort contributed by the employees and reward given by the employers violates the psychological contract between both parties. The reward distribution proposed by the ERI model also encompasses the job security aspect which is considered an important issue in the current working environment. In addition to the ERI model, the organizational justice model is related to organizational procedure in dealing with the employees. The organizational procedure refers to the perceived quality of managerial process and interpersonal relationship in the organization (Loi et al., 2011). Previously, the ERI and organizational injustice models were studied separately in most research. In a research by Kivimaki et al. (2007), the combination of these two stressors is found to cause greater health outcomes compared to the ERI or organizational injustice models alone. Therefore, the present research integrates the ERI model and organizational justice model to examine the effect of both models on psychological strain among the employees. The findings from the integration of ERI and organizational justice will help to design appropriate intervention strategies to improve employees' psychological strain.

\section{Literature Review}

\subsection{Effort-reward Imbalance Model}

Effort-reward imbalance is one of the models that explain psychosocial work environment leads to adverse employee's health outcomes. This model was introduced by Siegrist et al. (1996) based on reciprocity concept of social exchange theory. The ERI model postulates that effort spent by the employees at work should be exchanged with adequate rewards. A failed reciprocity between high effort spent and low reward received will then lead to negative effect on employee's health and well-being. There are three components of the ERI model which effort, reward and overcommitment. Effort-reward imbalance model posited three hypotheses involving the three components. The hypotheses are as follow:

i. Extrinsic hypothesis- The imbalance between high effort and low reward (i.e. effort-reward ratio) has a greater effect on employees' health and well-being as compared to individual effect of effort and reward component.

ii. Intrinsic hypothesis- Overcommitment impairs employees' health and well-being without considering the effort-reward condition.

iii. Interaction hypothesis- The interaction between effort-reward mismatch and overcommitment increase the negative effect on health and well-being.

\section{Effort}

The concept of effort is related to the demanding aspects of work such as responsibilities, obligations, datelines and work interruptions (Kinman \& Jones, 2008; Van Vegchel et al., 2005). Effort is spent by an employee to accomplish the required tasks at work. Therefore, effort is concerned with the concept of job demand that has been proposed by Karasek (1979). Job demands refers to those physical, psychological, social or organisational aspects of the job that require sustained physical or psychological (cognitive and emotional) effort and are therefore associated with certain physiological and psychological costs. Since effort is always refer to the situational aspects of work (i.e. responsibilities, obligations, datelines and work interruptions), it is often known as the extrinsic effort (Siegrist, 1999).

Van Vegchel and colleagues (2001) have classified effort into three categories namely psychological demand, emotional demand and physical demand. Psychological demand usually deals with employee's mental determination in completing the job such as working under time pressure and facing job complexity. Emotional demand is closely related to the affective aspect of job demand. For example, the job requires the employee to have high emotional quotient such as in confronting clients with counter-productive behaviour. Physical demand refers to job that involves physical burden and activities such as carrying heavy loads and prolonged awkward position. Siegrist and colleagues (2004) has suggested physical workload is only suitable for the occupational groups where physical workloads one of their typical task.

\section{Reward}

Reward is the organizational gratification that an employee gained after giving contribution to the organization. 
There are two types of rewards in the organization namely tangible and intangible reward. The examples of tangible reward are salary increases and job promotion while the intangible rewards can be seen through an employee's satisfaction of being treated by the employer. Reward is one of the important aspects to maintain a healthy workplace. Grawitch and colleagues (2007) has highlighted five sets of healthy workplace practices including employee recognition programs and policies that provide monetary rewards such as compensation and bonuses, the celebration of milestones within the organization and nonmonetary rewards such as award giving.

In the ERI model, reward is categorized into three types which are esteem reward, financial reward and promotion or security prospect (Siegrist et al., 2004). Esteem reward involves the recognition and approval from the superior and colleagues. Financial reward is related to financial gain received by the employee such as salary, bonuses and compensation. Promotion or security prospect types of reward refer to the security to stay working in the current job condition and the probability for job advancement and development by being promoted to higher level of job.

\section{Effort-reward Ratio}

Effort-reward ratio is measured by combining the two dimensions of the ERI model which are effort and reward construct. This is the central proposition of the ERI model where the ERI model posits that imbalance of the effort-reward ratio will lead to negative outcomes at work specifically psychological strain (Siegrist et al., 1996). The effect of effort-reward imbalance on strain in the ERI model is also known as the extrinsic ERI hypothesis.

In the earlier development of ERI, research investigated the impact of high effort-low reward condition on employees' physical health mainly cardiovascular disease (Allisey, 2012; Siegrist, 1996). Other physical consequences of ERI are cellular immunity (Nakata et al., 2011) and obesity (Inoue et al., 2010). The existence of ERI is also found to significantly predict psychological outcomes at work. Among these outcomes are anxiety, depressive symptom, perceived stress and mild mental disorder symptoms (Van Vegchel et al., 2005).

\section{Overcommitment}

Siegrist (1999) introduced overcommitment as an intrinsic or personal component that influences the perception of both effort and reward. Overcommitment has been defined as "a set of attitudes, behaviours and emotion that reflect excessive striving in combination with a strong desire to be approved of and esteemed" (Siegrist, 2001, p. 55). Overcommitted employees exaggerate their effort beyond what is needed in order to gain rewards. In the ERI model, overcommitment functions as a moderator between high effort and low reward with strain. Overcommitment is considered as a cognitive-motivational pattern of maladaptive coping with high job demand which prevents the employee to withdraw from work and obligations (Siegrist et al., 2004).

\subsection{Organizational Justice}

Another psychosocial determinant of employee health is organizational justice. Organizational justice refers to the extent to which employee perceive the organization is being fair to them. According to justice theory, an unfair treatment towards members leads to counter-productive behaviours in a group, including in an organization (Kenny \& McIntyre, 2005). This research utilized two types of organizational justice namely procedural justice and interactional justice.

\section{Procedural Justice}

Procedural justice is defined as the perceived fairness of the process leading to certain decision or distribution of outcomes, despite the results of the distribution (Spector, 2007). This type of justice was introduced by Thibaut \& Walker (1975) referring to voice or control an individual have in decision-making process. Leventhal (1976) has identified eight criteria that contribute to employees' perception of a decision process. The criteria are consistency across time, consistency across persons, neutrality, accuracy, correctability, representativeness, morality and ethicality. Later, Colquitt (2001) pointed out seven criteria which are process control, decision control, consistent, free of bias, accuracy, correctibility and ethicality.

Procedural justice theory has been widely applied to the workplace, with research finding that employees place great value on procedural justice (Lind \& Tyler, 1988; Tyler et al., 1997). Without fairness in the procedure executed by the organization, employee will feel threaten. This will then lead to the adverse effects towards the employee's health and work outcomes such as organizational commitment (Aizzat Mohd. Nasurdin \& Zainal Ariffin Ahmad, 2001). In addition, procedural justice is not truly instrumental whereby an employee will look forward a fair procedure even when procedure does not affect the outcomes (Lind et al., 1990; Tyler et al., 1997).

\section{Interactional Justice}

Organizational justice researchers developed the notion of interactional justice, defined as the quality of 
interpersonal treatment received during the enactment of organizational procedures (Bies \& Moag, 1986). In general, interactional justice reflects concerns about the fairness of the non-procedurally dictated aspects of interaction; however, research has identified two subcategories of interactional justice: informational justice and interpersonal justice (Folger \& Cropanzano, 1998). These two subcategories of informational and interpersonal justice overlap considerably; however, research suggests that they should be considered separately, as each has differential effects on justice perceptions (Colquitt, 2001; Colquitt et al., 2001). Interactional justice includes various actions displaying social sensitivity, such as when supervisors treat employees with respect and dignity.

\subsection{Conceptual Framework}

Predictor variables

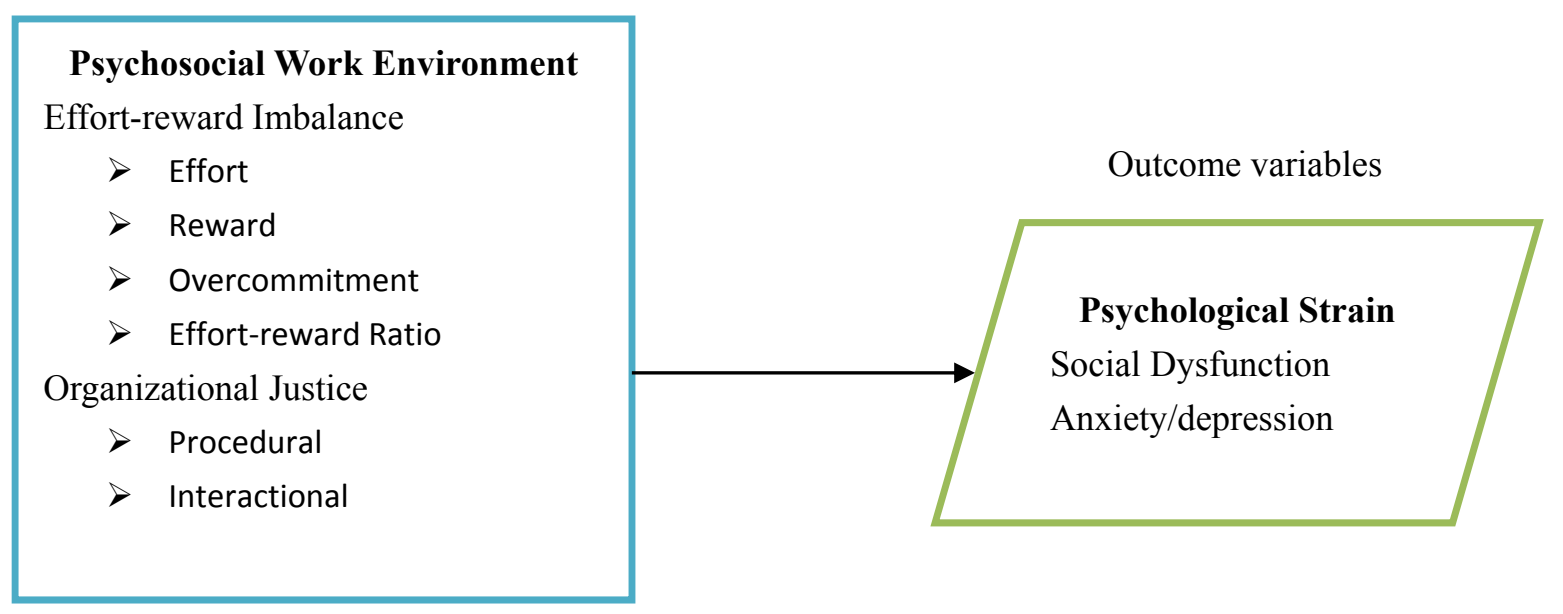

Figure 1. Conceptual Framework

Figure 1 illustrated the conceptual framework of the current research. The predictor in this research is psychosocial work environment elements that have been postulated in the effort-reward imbalance (ERI) model and organizational justice model. The psychosocial working environments in these models are related to the individual, collective and organizational aspects of the occupational activity. In particular, they include work contract and organizational procedure. The inequity between effort and reward as postulated by the ERI model is related to work contract that exist between the employers and their employees. Meanwhile, procedural justice and interactional justice from the organizational justice model are associated with organizational procedure which involves fair treatment towards an individual employee. Aside from job-related elements specificly effort and reward, the integration of the individual elements from the ERI model (i.e. overcommitment) and social elements from organizational justice model draws a comprehensive model of psychosocial work environment model. Both ERI model and organizational model proposed that the aspects of psychosocial work environment lead to emotional distress or psychological strain. According to the cognitive theory by Lazarus (1991), cognitive evaluation of an experienced stressor precedes negative emotional response. Thus, psychological strain is predicted as the result from cognitive appraisal of stressful psychosocial work environment. In sum, this research hypothesizes that psychosocial work environment (i.e. effort, reward, effort-reward ratio, overcommitment, procedural justice, interactional justice) will affect psychological strain.

\section{Methodoloogy}

\subsection{Sample and Procedure}

This research employed quantitative data collection method by distributing a set of questionnaires. The research population involved bank tellers in a local-based bank in Malaysia. This research utilized simple random sampling method. A total of 306 respondents answered the questionnaires.

\subsection{Research Instrument}

Effort-reward Imbalance Questionnaire - This research applied the short-version of Effort-reward Imbalance Questionnaire (Siegrist, 2004) to measure the components of effort-reward imbalance. This short version consists of 16 items. All of the items showed high realibility with Alpha Cronbach values for effort, reward, and overcommitment were $0.91,0.93$ and 0.91 respectively. The effort-reward ratio was calculated by placing the 
effort score in the numerator and the reward score in the denominator. The reward score was multiplied by a correction factor of 0.43 because of an unequal number of items in the numerator and denominator (6/11). A value close to zero indicates a favourable condition (relatively low effort, relatively high reward), whereas values beyond 1.0 indicate a critical condition of high costs (efforts) and low gain (rewards). The result of confirmatory factor analysis showed that the effort-reward imbalance was a three-factor model incorporating effort, reward and overcommitment with acceptable model fit $(\mathrm{X} 2=286.03, \mathrm{X} 2 / \mathrm{df}=2.98, \mathrm{RMR}=0.07, \mathrm{RMSEA}=0.08, \mathrm{CFI}=$ $0.95, \mathrm{GFI}=0.89, \mathrm{AIC}=366.03, \mathrm{CAIC}=554.98$ ). The factor loading of each items ranged from 0.66 to 0.94 .

Organizational Justice Scale - The researchers utilized Organizational Justice Scale by Neihoff and Moorman (1993) to measure both procedural justice and interactional justice. This instrument comprises of consists of seven items that measure procedural justice and six items that measure interactional justice. The Alpha Cronbach value for procedural justice was 0.94 while the Alpha Conbach value for interactional justice was 0.98 . The result of confirmatory factor analysis showed that the two-factor model of organizational justice incorporating procedural justice and interactional justice factors with acceptable model fit $(\mathrm{X} 2=247.63, \mathrm{X} 2 / \mathrm{df}=2.91$, $\mathrm{RMR}=0.05, \mathrm{RMSEA}=0.08, \mathrm{CFI}=0.97, \mathrm{GFI}=0.91, \mathrm{AIC}=317.63, \mathrm{CAIC}=482.96)$. The range of the items factor loading was 0.72 to 0.95 .

General Health Questionnaire-12 - This research measured psychological strain using the 12 items General Health Questionnaire by Goldberg and Huxley (1988). Psychological strain was divided into two namely anxiety/depression and social dysfunction as resulted from the confirmatory factor analysis. After conducting the factor analysis, the two-factor model yielded a good fit $(\mathrm{X} 2=135.46, \mathrm{X} 2 / \mathrm{df}=2.88, \mathrm{RMR}=0.05, \mathrm{RMSEA}=0.08$, $\mathrm{CFI}=0.98, \mathrm{GFI}=0.93, \mathrm{AIC}=197.46, \mathrm{CAIC}=343.89)$. All of the items were highly represented the two factors of anxiety/depression and social dysfuction with factor loading ranging from 0.81 to 0.95 . In terms of reliability, the Alpha Cronbach value for anxiety/depression and social dysfuction were both 0.96 .

\subsection{Data Analysis}

Structural Equation Modelling (SEM) by AMOS 18 was used to test the main effects between variables. Specifically, the latent analysis in SEM was utilized to test the main effect of psychosocial work environment dimension on psychological strain.

\section{Results}

\subsection{Demografic Profile}

In terms of the demographic profile of the respondents $49.3 \%$ were male while $50.7 \%$ were female. The ages ranged from 22-39 years (mean $=30.5, \mathrm{SD}=3.8)$. Most of the respondents were Muslim $(92.8 \%)$, followed by, Hindu (3.3\%), Buddha (2.6\%) and Christian (1.3\%). Their marital status showed that $74.5 \%$ of them were married, $24.2 \%$ of them were single and $1.3 \%$ of them were divorced. In terms of education, $23.2 \%$ of them obtained SPM, 42.8\% STPM, 32.7\% diploma, and 1.3\% bachelor degree. Most of the respondents recorded job tenure more than five years $(66.0 \%)$, followed by three to five years tenure $(16.3 \%)$, one to three years tenure $(14.4 \%)$, and less than 1 year tenure $(3.3 \%)$. In terms of salary, most of them received salary that ranged from RM2000 to RM2999 (66.7\%) and followed by RM1000 to RM1999 (33.3).

\subsection{Descriptive and Correlational Analysis}

Table 1 demonstrates the mean, standard deviation and inter-correlation among the studied variables. Overall, the results reported moderate levels of effort, reward, overcommitment, procedural justice, interactional justice and anxiety/depression with the mean value ranged between 2.71 to 3.08 . Only the level of social dysfunction was found low with mean value of 2.91 (considered low for a six-scale measure). The standard deviation value for all variables ranged from 0.80 to 1.35 .

The correlation among the ERI components reported high correlation. Effort-reward ratio showed the strongest correlation with reward $(\mathrm{r}=0.831, \mathrm{p}<0.01)$. Procedural justice and interactional justice correlate moderately with each other. All of the psychosocial work environment dimensions moderately correlate with both anxiety/depression and social dysfunction. Overall, all the study variables correlated with each other in the expected direction. 
Table 1. Mean, Standard Deviation and Intercorrelation between the Study Variables (N=306)

\begin{tabular}{lllllllllll}
\hline Variables & Mean & SD & 1 & 2 & 3 & 4 & 5 & 6 & 7 & 8 \\
\hline 1 Effort & 2.99 & 1.01 & - & & & & & & & \\
2 Reward & 2.67 & 0.94 & $-.602^{* *}$ & - & & & & & \\
3 Effort-reward Ratio & 1.43 & 0.89 & $.740^{* *}$ & $-.831^{* *}$ & - & & & & \\
4 Overcommitment & 3.04 & 0.80 & $.742^{* *}$ & $-.553^{* *}$ & $.586^{* *}$ & - & & & \\
5 Procedural Justice & 2.71 & 0.79 & $-.451^{* *}$ & $.568^{* *}$ & $-.549^{* *}$ & $-.393^{* *}$ & - & & & \\
6 Interactional Justice & 3.08 & 0.89 & $-.437^{* *}$ & $.603^{* *}$ & $-.541^{* *}$ & $-.414^{* *}$ & $.603^{* *}$ & - & & \\
7 Anxiety/depression & 3.07 & 1.35 & $.662^{* *}$ & $-.634^{* *}$ & $.588^{* *}$ & $.676^{* *}$ & $-.416^{* *}$ & $-.568^{* *}$ & - & \\
8 Social Dysfunction & 2.91 & 1.11 & $.513^{* *}$ & $-.617^{* *}$ & $.558^{* *}$ & $.503^{* *}$ & $-.508^{* *}$ & $-.535^{* *}$ & $.709^{* *}$ & - \\
\hline
\end{tabular}

Note $^{* *}$ Significant at $\mathrm{p}<0.01$

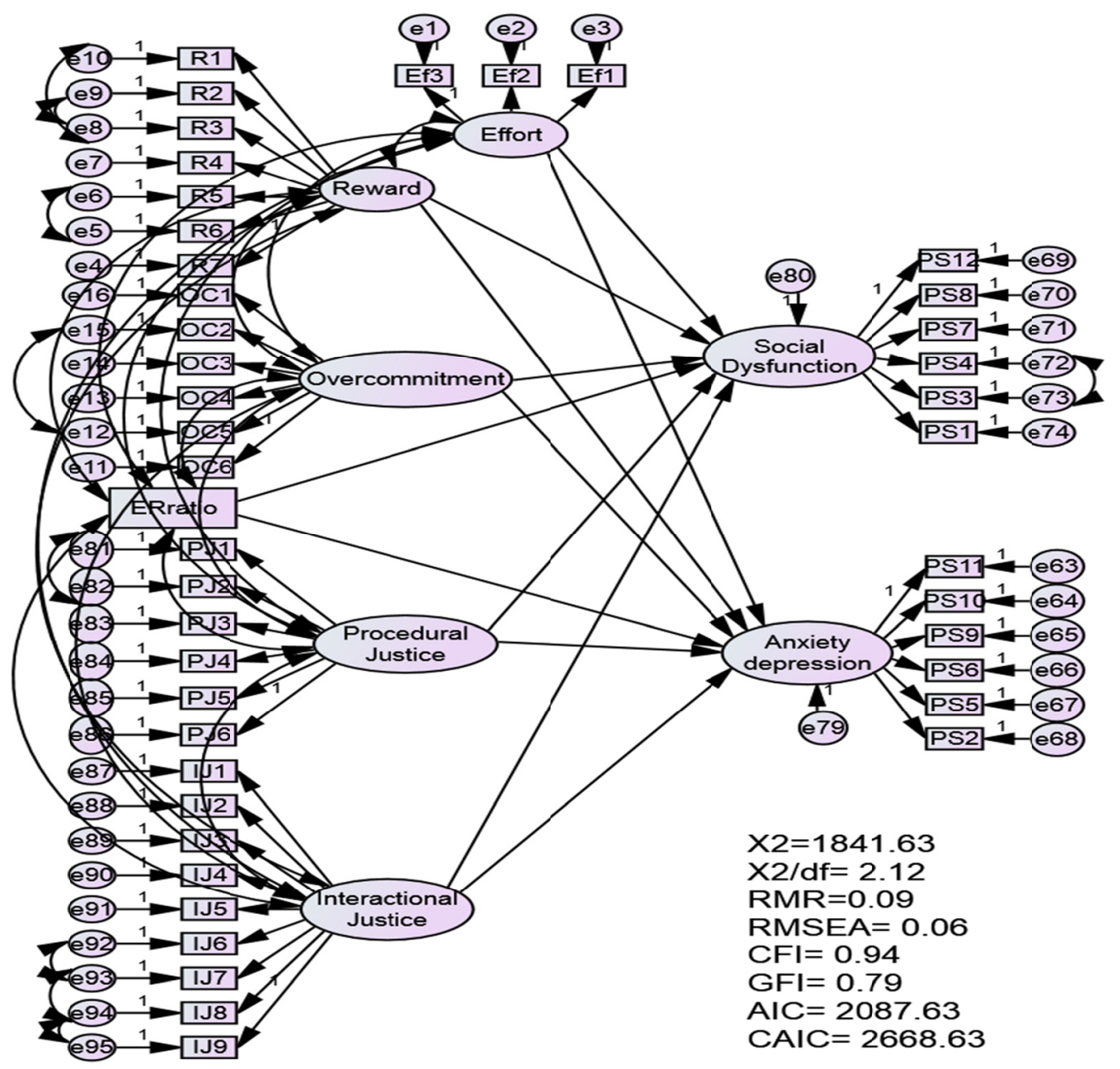

Figure 2. Structural model for the direct effect between psychosocial work environment and psychological strain

Figure 2 illustrates the structural models for the direct effects of psychosocial work environment dimensions (i.e. effort, reward, effort-reward ratio, overcommitment, procedural justice and interactional justice) on anxiety/depression and social dysfunction. All of the items showed acceptable factor loading ranging from 
0.66-0.95. The model yielded an acceptable fit with $\mathrm{X} 2=1841.63, \mathrm{X} 2 / \mathrm{df}=2.12, \mathrm{RMR}=0.09, \mathrm{RMSEA}=0.06$, $\mathrm{CFI}=0.94, \mathrm{GFI}=0.79, \mathrm{AIC}=2087.63, \mathrm{CAIC}=2668.63$

Table 2 summarizes the effects of psychosocial work environment dimensions on psychological strain. The results revealed several significant findings. First, overall, psychosocial work environment contributed 55.3\% towards anxiety/depression and $41.7 \%$ towards social dysfunction. Second, effort and effort-reward ratio were only significant to positively affect anxiety/depression but not significant on social dysfunction. Thus, higher level of effort and effort-reward ratio increases the level of anxiety/depression. Third, reward, procedural justice and interactional justice showed significant negative effects on both anxiety/depression and social dysfunction. Hence, higher level of reward, procedural justice and interactional justice decrease the level of anxiety/depression and social dysfunction. Fourth, overcommitment was found to positively affected anxiety/depression and social dysfunction. Therefore, the employees with higher level of overcommitment suffer greater anxiety/depression and social dysfunction. In sum, the results partially supported the research hypothesis where only several dimensions of psychosocial work environment affected the two dimensions of psychological strain.

Table 2. Effects of psychosocial work environment dimensions on psychological strain

\begin{tabular}{lllll}
\hline Structural Path & $\mathrm{B}$ & $\mathrm{S} . \mathrm{E}$. & $\mathrm{C} . \mathrm{R}$. & $\mathrm{R}^{2}$ \\
\hline Effort $\rightarrow$ Anxiety/Depression & $.289^{* *}$ & .133 & 3.319 & .553 \\
Reward $\rightarrow$ Anxiety/Depression &.$- .259^{* *}$ & .131 &.-2.749 & \\
Effort/reward Ratio $\rightarrow$ Anxiety/Depression & $-.179^{*}$ & .173 & -1.655 & \\
Overcommitment $\rightarrow$ Anxiety/Depression & $.288^{* *}$ & .116 & 4.161 \\
Procedural Justice $\rightarrow$ Anxiety/Depression & -.058 & .086 & .946 \\
Interactional Justice $\rightarrow$ Anxiety/Depression & $-.291^{* *}$ & .080 & -5.122 & \\
Effort $\rightarrow$ Social Depression & .100 & .120 & 1.051 & .417 \\
Reward $\rightarrow$ Social Depression & $-.260^{* *}$ & .120 & -2.494 & \\
Effort/reward Ratio $\rightarrow$ Social Depression & -.036 & .158 & -.299 & \\
Overcommitment $\rightarrow$ Social Depression & $.157^{*}$ & .104 & 2.096 & \\
Procedural Justice $\rightarrow$ Social Depression & $-.138^{*}$ & .079 & -2.251 & \\
Interactional Justice $\rightarrow$ Social Depression & $-.202^{* *}$ & .072 & -3.232 & \\
\hline
\end{tabular}

\section{Discussion and Conclusion}

The aim of this study is to investigate the effect of psychosocial work environment on psychological strain by investigating the effort-reward imbalance and organizational justice components. The findings indicated that effort-reward imbalance and organizational justice components exhibits significant effect on employees' psychological strain. These significant effects supported that psychological strain are predicted by a wider range of social context rather than focusing only on the give and gain reciprocity experienced by the employees. The effect of ERI model and organizational justice model complement each other as the predictors of strain (Kivimaki et al., 2007).

The extrinsic hypothesis of the ERI model was not fully supported in this study since the effect of effort-reward ratio was only significant on anxiety/depression but not on social dysfunction. This finding suggested that the adequacy of organizational reward for the effort spent at work is not necessarily important to employees. A plausible explanation for this is the employees might posses a high level of a certain characteristics that could reduce the effect of effort-reward imbalance on health and well-being such as self-reliance and self-efficacy (Siegrist, 2002). In addition, the individual effect of reward on psychological strain indicated that sufficient reward itself is vital to prevent unhealthy outcomes whether the effort was highly spent or not. This might be due to the present economic condition that comprehends the soaring of living costs, the power of social recognition and the limited job opportunity. .

Furthermore, effort individually showed a significant positive effect on anxiety/depression but not on social dysfunction. This finding can be supported by the research conducted by Siti Aisyah Panatik (2010) which found 
job demand significantly affected anxiety/depression but not social dysfunction. The concept of effort is similar to job demand characteristic in the Job Demand Control Model where effort represented the demanding aspects of work such as time pressure and workload. Due to banking restructuring nowadays, employees have another role as customer service representative. Instead of just performing traditional clerical work in the bank branch, they also have to contribute with the sales of the banking products such as insurance policy and trust funds (Khoo, 2012).

The finding of overcommitment that significantly contributed to anxiety/depression and social dysfuction supported the intrinsic hypothesis of the ERI model. The intrinsic of ERI model proposed overcommitment as a personal characteristic that directly affected health and well-being (Siegrist, 2001). Overcommitment represents the need for control over the environment (Siegrist, 1999). The inclusion of overcommitment distinguish ERI model from othe psychosocial work environment measures. In working context, employees with high overcommitment tend to exaggerate their effort even when they are not on the job (Siegrist, 2001). The failure to withdraw from work by overcommitted employees resulted in adverse physical and psychological health whether (Silva \& Barreto, 2010; Preckel et al., 2007; Tsutsumi \& Kawakami, 2004).

The significant effects of both organizational components on anxiety/depression and social dysfunction corroborated previous research findings. Employees who were exposed to organizational injustice reported higher level of psychological strain (Francis \& Barling, 2005). Since strain is the reaction of stress, organizational justice might affect psychological strain through prolonged stress (Elovainio et al., 2013). This finding is relevant to the literature on the effects of organizational justice on mental health. Low procedural justice and low interactional justice was found to be associated with major depressive episodes (Inoue et al., 2013) and absences due to mental sickness (Elovainio et al., 2013)

The strength of this research is the integration of the ERI model and organizational justice model to predict psychological strain. ERI components incorporated with procedural and interactional justice provide a wider picture of psychosocial work environment. These components cover the social contract between the bank and the employees, the management procedure, the superior-teller interaction as well as individual difference which potentially risks tellers' strain. The limitation of this study is the cross-sectional research design whereby the researcher could not investigate the long term effect of the predictors on psychological strain. Future research should explore more psychosocial work environment components that might affect employee's health and well-being. Besides that, future researcher may conduct longitudinal or mixed method research on the same topic to obtain a more in-depth finding. In conclusion, this study provides insight on the psychological work environment research that investigates ERI and organizational justice components as risk factors of psychological strain; specifically among bank employees in Malaysian setting.

In conclusion, this research revealed the role of psychosocial work environment as the predictor to employees' psychological strain. The integration of the ERI model and organizational model represent a broader range of psychosocial factors in the organization. Additional research is needed to support the current research findings in other sectors as well as to study other psychosocial factors as potential predictors of psychological strain.

\section{Acknowledgements}

Thank you to the Malaysia Ministry of Higher Education and Universiti Teknologi Malaysia (UTM). This research is being sponsored by MyBrain $15(\mathrm{MyPhD})$.

\section{References}

Aizzat Mohd Nasurdin \& Zainal Ariffin Ahamad. (2001). The effect of procedural justice on organizational commitment in the Malaysian context: Do men and women differ? Asian Academy of Management Journal, $6(1), 31-47$.

Allisey, A. (2011). Clarifying the effort-reward imbalance model: The role of personality. Deakin University.

Ang, W. L., Bahron, A., \& Boroh, R. P. (2014). A study on role stress and job satisfaction among bank employees in Kota Kinabalu, Sabah. International Journal of Research in Management \& Business Studies, $1(2), 19-23$.

Bakker, A. B., \& Demerouti, E. (2007). The Job Demands-Resources model: state of the art. Journal of Managerial Psychology, 22(3), 309-328. http://dx.doi.org/10.1108/02683940710733115

Bank Negara Malaysia. (2013). Financial Sector Development. Retrieved from http://www.bnm.gov.my/ index.php

Bies, R. J., \& Moag, J. S. (1986). Interactional justice: Communication criteria of fairness. Greewich: Jai Press. 
Calnan, M., Wainwright, D., \& Almond, S. (2000). Job strain effort-reward imbalance and mental distress: A study of occupations in general medical practice. Work and Stress, 14, $297-311$. http://dx.doi.org/10.1080/02678370110040920

Colquitt, J. A. (2001). On the Dimensionality of Organizational Justice: A Construct Validation of a Measure. Journal of Applied Psychology, 86(3), 386-400. http://dx.doi.org/10.1037//0021-9010.86.3.386

Elovainio, M., Linna, A., Virtanen, M., Oksanen, T., Kivimaki, M., Pentti, J., \& Vahtera, J. (2013). Perceived organizational justice as a predictor of long term sickness absence due to diagnosed mental disorder: Results from the prospective longitudinal Finnish public sector study. Social Science \& Medicine, 91, 39-47. http://dx.doi.org/10.1016/j.socscimed.2013.05.008

Folger, R., \& Cropanzano, R. (1998). Organizational justice and human resource management. Thousand Oaks, California: Sage Publication Inc.

Francis, L., \& Barling, J. (2005). Organizational injustice and psychological strain. Canadian Journal of Behavioural Science, 37 (4), 250-261. http://dx.doi.org/10.1037/h0087260

Ganster, D. C. (2008). Measurement challenges for studying work-related stressors and strains. Human Resource Management Review, 18, 12. http://dx.doi.org/10.1016/j.hrmr.2008.07.011

Goldberg, D., \& Williams, P. (1988). GHQ: A user's guide to the General Health Questionnaire. Windsor: NFER/Nelson, Windsor

Grawitch, M. J., Trares, S., \& Kohler, J. M. (2007). Healthy workplace practices and employee outcomes. International Journal of Stress Management, 14(3), 275-293. http://dx.doi.org/10.1037/1072-5245.14.3.275

Griffin, J. M., Greiner, B. A., Stansfeld, S. A., \& Marmot. M. (2007). The effect of self-reported and observed job conditions on depression and anxiety symptoms: A comparison of theoretical models. Journal of Occupational Health Psychology, 12(4), 334-349. http://dx.doi.org/10.1037/1076-8998.12.4.334

Idris, M. K. (2011). Over time effects of role stress on psychological strain among Malaysian public university academics. International Journal of Business and Social Science, 2, 154-161.

Inoue, A., Kawakami, N., Ishizak, M., Shimazu, A., Tsuchiya, M., Tabata, M., et al. (2010). Organizational justice, psychological distress, and work engagement in Japanese workers. International Archives of Occupational and Environmental Health, 83, 29-38. http://dx.doi.org/10.1007/s00420-009-0485-7.

Inoue, A., Kawakami, N., Tsuno, K., Tomioka, K., \& Nakanishi, M. (2013). Organizational justice and major depressive episodes in Japanese employees: A cross-sectional study. Journal of Occupational Health, 55, 47-55. http://dx.doi.org/10.1539/joh.12-0131-OA

Inoue, M., Tsurugano, S., Nishikitani, M., \& Yano, E. (2010). Effort-reward imbalance and its association with health among permanent and fixed-term workers. BioPsychoSocial Medicine, 4. http://dx.doi.org/10.1186/1751-0759-4-16

Karasek, R. A. (1979). Job demands, job decision latitude, and mental strain: Implication for job redesign. Administrative Science Quarterly, 24, 285-308. http://dx.doi.org/10.2307/2392498

Kenny, D., \& McIntyre, D. (2005). Constructions of occupational stress: nuisances, nuances or novelties. In Alexander-Stamatios, G. Antonio, \& C. L. Cooper (Eds.), Research Companion to Organizational Health Psychology. United Kingdom: Cornwall.

Khoo, S. L. (2012). What does the new economy mean to Malaysian tellers? Just Labour: A Canadian Journal of Work and Society, 19, 47-58.

Kinman, G., \& Jones, F. (2008). Effort-reward Imbalance, Over-commitment and Work-life Conflict: Testing an Expanded Model. Journal of Managerial Psychology, 23(3). http://dx.doi.org/10.1108/02683940810861365

Kivimäki, M., Ferrie, J. E., Brunner, E., Head, J., Shipley, M. J., Vahtera, J., et al. (2005). Justice at work and reduced risk of coronary heart disease among employees: The Whitehall II Study. Archives of Internal Medicine, 165(19), 2245-2251. http://dx.doi.org/10.1001/archinte.165.19.2245

Kivimaki, M., Honkonen, T., Wahlbeck, K., Elovainio, M., Pentti, J., Klaukka, T., et al. (2007). Organisational downsizing and increased use of psychotropic drugs among employees who remain in employment. Journal of Epidemiol Community Health, 61, 154-158. http://dx.doi.org/10.1136/jech.2006.050955

Kivimäki, M., Vahtera, J., Elovainio, M., Virtanen, M., \& Siegrist, J. (2007). Effort-reward imbalance, procedural injustice and relational injustice as psychosocial predictors of health: complementary or 
redundant models? Occupational and Environmental Medicine, 64(10), 659-665. http://dx.doi.org/10.1136/oem.2006.031310

Lazarus, R. S. (1991). Progress on a cognitive-motivational-relational theory of emotions. American Psychologist, 46, 819-834. http://dx.doi.org/10.1037/0003-066X.46.8.819

Leventhal, G. S. (1976). The distribution of rewards and resources in groups and organizations (Vol. 9). New York: Academic Press.

Lind, E. A., \& Tyler, T. R. (1988). The Social Psychology of Procedural Justice. Plenum, New York.

Loi, R., Lam, L. W., \& Chan, K. W. (2011). Coping with job insecurity: The role of procedural justice, ethical leadership and power distance orientation. Journal of Business Ethics. http://doi.org/10.1007/S10551-0111095-3

Nakata, A., Takahashi, M., \& Irie, M. (2011). Effort-reward imbalance, overcommitment, and cellular immune measures among white-collar employees. Biological Psychology, 88(2-3), 270-279. http://dx.doi.org/10.1016/j.biopsycho.2011.08.012

Niehoff, B. P., \& Moorman, R. H. (1993). Justice as a mediator of the relationship between methods of monitoring and organizational citizenship behavior. Academy of Management Journal, 36, 527-556.

O'Driscoll, M. P., \& Brough, P. (2010). Work organizaton and health. In S. Leka, \& J. Houdmont (Eds.), Occupational health psychology (pp. 57-87). United Kingdom: Wiley-blackwell.

Panatik, S. A. (2010). Impact of work design on psychological work reactions and job performance among technical workers: A longitudinal study in Malaysia. The University of Waikato, Hamilton, New Zealand.

Preckel, D., Meinel, M., Kudielka, B. M., Haug, H. J., \& Fischer, J. E. (2007). Effort-reward-imbalance, overcommitment and self-reported health: Is it the interaction that matters. Journal of Occupational and Organizational Psychology, 80, 91-107. http://dx.doi.org/10.1348/096317905X80183

Sharma, S., \& Sharma, M. (2010). Globalization, threatened identities, coping and well-being. Psychological Studies, 55(4), 313-322. http://dx.doi.org/10.1007/s12646-010-0048-8

Siegrist, J. (1996). Adverse health effects of high-effort/low-reward conditions. Journal of Occupational Health Psychology, 1(1), 27-41. http://dx.doi.org/10.1037//1076-8998.1.1.27

Siegrist, J. (1999). Occupational health and public health in Germany. In P. M. L. Blanc, M. C. W. Peeters, A. Bussing, \& W. B. Schaufeli (Eds.), Organizational Psychology and Health Care (pp. 35-44). Munchen: Rainer Hampp Verlag.

Siegrist, J. (2001). A theory of occupational stress. In J. Dunham (Ed.), Stress in the Workplace, Past, Present and Future. London: Whurr Publishers.

Siegrist, J. (2002). Effort-reward imbalance and health in a globalized economy. Scandinavian Journal of Work, Environment \& Helath Supplements, (6), 163-168.

Siegrist, J. (2009). Unfair exchange and health: Social bases of stress-related diseases. Social Theory and Health, 7(4), 305-317. http://dx.doi.org/10.1057/sth.2009.17

Siegrist, J., \& Peter, R. (1996). Threat to occupational status control and cardiovascular risk. Israel Journal of Medical Sciences, 32, 179-184.

Siegrist, J., Li, J., \& Montano, D. (2014), Psychometric properties of the effort-reward imbalance questionnaire. Retrieved from http://www.uniklinik-duesseldorf.de/fileadmin/Datenpool/einrichtungen/institut_fuer_medizinische_soziolo gie_id54/ERI/PsychometricProperties.pdf

Siegrist, J., Starke, D., Chandola, T., Godin, I., Marmot, M., \& Niedhammer, I. (2004). The measurement of effort-reward imbalance at work: European comparisons. Social Science and Medicine, 58(8), 1483-1499.

Silva, L. S., \& Barreto, S. M. (2010). Adverse psychosocial working conditions and minor psychiatric disorders among bank workers . BMC Public Health, 10, 686. http://dx.doi.org/10.1186/1471-2458-10-686.

Silva, L. S., \& Barreto, S. M. (2012). Stressful working conditions and poor self-rated health among financial services employees. Rev Saúde Pública, 46(3), 407-16. http://dx.doi.org/10.1590/S0034-891020120050 00023

Spector, P. E. (2007). Industrial and organizational behaviour. United States of America: John Wiley \& Sons. 
Tepper, B. J. (2001). Health consequences of organizational injustice: Tests of main and interactive effects. Organizational Behavior and Human Decision Processes, 86, 197-215. http://dx.doi.org/10.1006/obhd.2001. 2951

Thibaut, J., \& Walker, L. (1975). Procedural justice: A psychological analysis. New Jersey: Lawrence Erlbaum Associates.

Tsutsumi, A., \& Kawakami, N. (2004). A review of empirical studies on the model of effort-reward imbalance at work: Reducing occupational stress by implementing a new theory. Social Science and Medicine, 59, 2335-2359. http://dx.doi.org/10.1016/j.socscimed.2004.03.030

Tyler, T. R., Boeckmann, R. J., Smith, H. J., \& Huo, Y. J. (1997). Social Justice in a Diverse Society. Westview, Boulder, CO.

Van Vegchel, N., De Jonge, J., Bosma, H., \& Schaufeli, W. (2005). Reviewing the effort-reward imbalance model: Drawing up the balance of 45 empirical studies. Social Science and Medicine, 60(5), 1117-1131. http://dx.doi.org/10.1016/j.socscimed.2004.06.043

Van Vegchel, N., De Jonge, J., Meijer, T., \& Hamers, J. P. (2001). Different effort constructs and effort-reward imbalance: effects on employee wellbeing. Journal of Advanced Nursing, 34(1), 128-136. http://dx.doi.org/10.1046/j.1365-2648.2001.3411726.x

\section{Copyrights}

Copyright for this article is retained by the author(s), with first publication rights granted to the journal.

This is an open-access article distributed under the terms and conditions of the Creative Commons Attribution license (http://creativecommons.org/licenses/by/3.0/) 